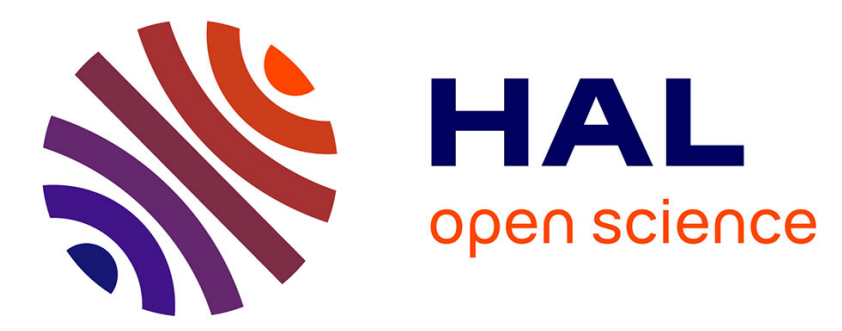

\title{
Raman scattering in InAsxSbyP1xy alloys grown by gas source MBE
}

K J Cheetham, A Krier, I I Patel, F L Martin, J-S Tzeng, C-J Wu, H-H Lin

\section{To cite this version:}

K J Cheetham, A Krier, I I Patel, F L Martin, J-S Tzeng, et al.. Raman scattering in InAsxSbyP1xy alloys grown by gas source MBE. Journal of Physics D: Applied Physics, 2011, 44 (8), pp.85405. 10.1088/0022-3727/44/8/085405 . hal-00597847

\section{HAL Id: hal-00597847 https://hal.science/hal-00597847}

Submitted on 2 Jun 2011

HAL is a multi-disciplinary open access archive for the deposit and dissemination of scientific research documents, whether they are published or not. The documents may come from teaching and research institutions in France or abroad, or from public or private research centers.
L'archive ouverte pluridisciplinaire HAL, est destinée au dépôt et à la diffusion de documents scientifiques de niveau recherche, publiés ou non, émanant des établissements d'enseignement et de recherche français ou étrangers, des laboratoires publics ou privés. 


\title{
Raman scattering in $\operatorname{InAs} s_{x} S b_{y} P_{1-x-y}$ alloys grown by gas source MBE
}

\author{
K J Cheetham ${ }^{1}$, A Krier ${ }^{1 *}$, I I Patel ${ }^{2}$, F L Martin², J-S Tzeng ${ }^{3}$, C-J Wu ${ }^{3}$ and H-H Lin ${ }^{3}$ \\ ${ }^{1}$ Physics Department, Lancaster University, Lancaster, LA1 4YB, United Kingdom \\ ${ }^{2}$ Centre for Biophotonics, Lancaster Environment Centre, Lancaster University, LA1 \\ 4YQ, United Kingdom \\ ${ }^{3}$ Graduate Institute of Electronics Engineering and Department of Electrical \\ Engineering, National Taiwan University, Taipei 10617, Taiwan
}

E-mail: a.krier@lancaster.ac.uk

\begin{abstract}
The Raman spectra of quaternary $\operatorname{InAs}_{\mathrm{x}} \mathrm{Sb}_{\mathrm{y}} \mathrm{P}_{1-\mathrm{x}-\mathrm{y}}$ epitaxial layers nominally lattice matched to (100) n-type InAs substrates are reported. The Phonon peaks are identified for alloys covering a wide composition range extending into the miscibility gap. Three-mode behaviour was obtained across part of the composition range. InP-like LO and TO phonons were observed over the entire compositional range, but InAs-like LO phonons were only observed at high arsenic concentrations and no InSb-like TO phonons were observed. Disorder related phonon peaks were obtained for alloy compositions within the miscibility gap.
\end{abstract}

PACS: 33.20.Fb, 63.20.-e, 68.55.ag, 78.20.-e, 78.30.-j, 78.30.Fs, 78.66.Fd

Submitted to: Journal of Physics D: Applied Physics

\section{Introduction}

The III-V quaternary alloys InAsSbP can conveniently provide access to semiconductors with energy band-gaps within the technologically important mid-infrared (2$5 \mu \mathrm{m})$ spectral range [1-2]. The presence of a fourth element also allows lattice-matched growth on InAs substrates. Using this approach it has been possible to produce mid-infrared LEDs [3-5], diode lasers [6-7], and photodetectors for detection of gases such as methane [8], carbon monoxide [9] or HF [10] as well as thermophotovoltaic cells [11]. However, there has been very little fundamental investigation of the InAsSbP material system and particularly for alloys grown by molecular beam epitaxy (MBE). In this work we report on the systematic spectroscopic investigation of InAsSbP alloys grown using gas source MBE. In particular we studied alloys which were lattice matched onto InAs substrates, covering almost the entire composition range and penetrating inside the miscibility gap [12].

Raman and infrared spectroscopy are powerful methods for the investigation of semiconductor alloys. For example, lattice vibrations at the characteristic longitudinal optical (LO) and transverse optical (TO) phonon frequencies can convey useful structural information about alloy composition, strain, bonding and the local environment of structure defects and impurities.

It is well known that for zinc blende semiconductors grown on (100) substrates, the TO mode is forbidden in Raman scattering due to selection rules. However, the weakening of selection rules caused by structural disorder or substrate misorientation breaks the symmetry and leads to the appearance of TO modes.

The Raman spectra of InAsSb, InPSb and InPAs III-V ternary alloys have been thoroughly investigated [13-15]. However, previous Raman studies on III-V quaternaries have focussed more on gallium containing compounds, such as GaInAsSb [16-17]. Whereas photoluminsence of InAsSbP has been extensively studied [18-19], vibrational studies are rare and limited to a small range of compositions [20-21]. Here we report on the detailed Raman spectroscopy of InAsPSb across a wide composition range.

\section{Experimental procedures}




\section{Raman scattering in $\operatorname{InAs}_{\mathrm{x}} \mathrm{Sb}_{\mathrm{y}} \mathbf{P}_{1-\mathrm{x}-\mathrm{y}}$ alloys grown by gas source MBE}

The samples for our investigation were grown by gas source MBE on (100) InAs substrates at a growth temperature of $470{ }^{\circ} \mathrm{C}$, using a VG-V80H reactor. The indium was provided by a thermal effusion cell, the antimony by an EPI effusion cell, and the arsenic and phosphorus came from cracked arsine and phosine gasses respectively, as detailed in a previous paper [16]. The fluxes of each of the materials were varied, with the phosphine adjusted from 990 to 300 Torr, to give a wide range of alloy compositions, all approximately lattice matched to InAs. In-situ monitoring of growth was carried out using reflection high energy electron diffraction to observe the condition of the growing epitaxial layer. The resulting layers were all $\sim 1 \mu \mathrm{m}$ thick and intentionally undoped.

The composition of the samples was determined using a JEOL JXA-8200 electron probe micro-analyser (EPMA) and are given in table 1. The system used for gathering the Raman spectra was a Renishaw InVia Raman spectrometer equipped with a 576x400 pixel Peltier cooled $\left(-70^{\circ} \mathrm{C}\right) \mathrm{CCD}$ detector. A spot size of $\sim 1.6 \mu \mathrm{m}^{2}$ was obtained using the $50 \mathrm{X}$ objective lens of a Leica DM2500M compound microscope. The spectral resolution obtained was $\sim 1 \mathrm{~cm}^{-1}$, using a 1200 line $/ \mathrm{mm}$ diffraction grating and a $50 \mu \mathrm{m}$ entrance slit. A $100 \mathrm{~mW}$ diode laser was used operating at $785 \mathrm{~nm}$ $(1.58 \mathrm{eV}$, higher than the band-gap of all the tested InAsSbP samples). The power incident on the sample was $\sim 40 \mathrm{~mW}$ after allowing for optical losses. A holographic notch filter was used to block out unwanted reflections. Scans from 100 to $800 \mathrm{~cm}^{-1}$ were taken at several locations on each sample, each with a run of 16 accumulations to reduce the effects of noise. An exposure time of $10 \mathrm{~s}$ was used to minimize heating effects with the sample at room temperature, however some local lattice heating is inevitable and results in peak broadening of the spectra.

\begin{tabular}{llll}
\hline Sample & As & Sb & P \\
\hline C1898 & 0.040 & 0.285 & 0.675 \\
C1899 & 0.092 & 0.283 & 0.625 \\
C1900 & 0.223 & 0.260 & 0.517 \\
C1767 & 0.361 & 0.228 & 0.411 \\
C1768 & 0.560 & 0.155 & 0.284 \\
C1770 & 0.681 & 0.099 & 0.220 \\
C2054 & 0.694 & 0.108 & 0.199 \\
C2055 & 0.730 & 0.109 & 0.161
\end{tabular}

$\begin{array}{llll}\mathrm{C} 2056 & 0.795 & 0.101 & 0.104\end{array}$

Table 1. Values of sample compositions determined from EMPA.

\section{Results and discussion}

Figure 1 shows the composition plane, along with spinodal curves calculated for different growth temperatures [22]. It can be clearly seen that the four low arsenic samples are therefore grown inside the immiscibility region.

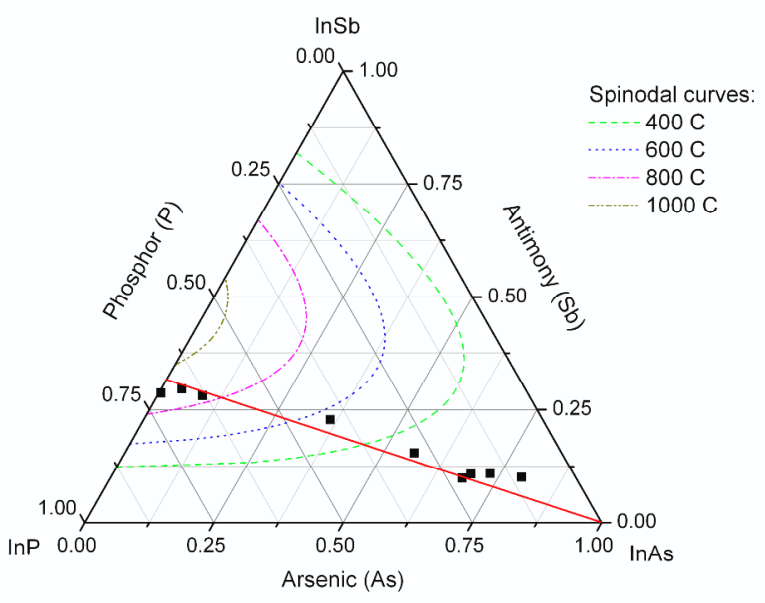

Figure 1. Experimental data and the InAsSbP alloy composition plane. Layers from this work are represented by black squares. The solid red line shows lattice matching to InAs.

Surface roughness can increase the background noise of Raman spectra due to enhanced diffuse scattering. In our case a large number of pits are observed at low arsenic concentrations and are probably due to arsenic vacancies. The optical quality of the sample surface was found to be improved by using an increased concentration of arsenic during growth. X-ray diffraction analysis revealed evidence of spinodal decomposition which has been described in detail in our previous publication [19].

The lattice constant of InAs is $6.0583 \AA$, and the calculated lattice mismatch of the grown layers was found to be less than $0.4 \%$, with only the samples within the immiscibility region having a lattice constant smaller than that of InAs. 


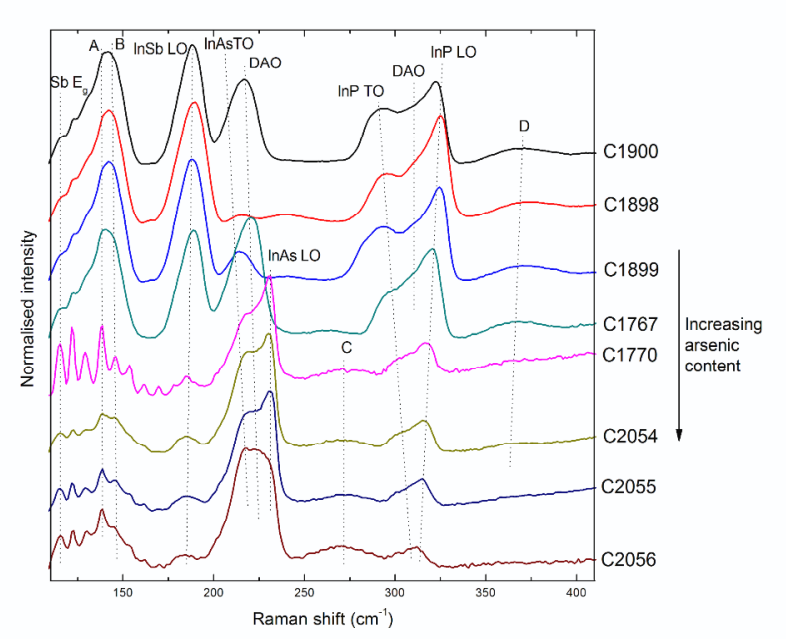

Figure 2. Room temperature Raman spectra of all the samples, with lines added as a guide to the eye showing the peak trends.

Figure 2 shows the Raman spectra measured from each of the samples. The peak assignment is primarily based on data from table 2. With an increase in the mole fraction of arsenic the InAs-like features dominate, as the corresponding modes have increased scattering intensity, and their frequency is closer to that of the end-point binary. The intensities of the peaks give an indication of the mode strength.

\begin{tabular}{lccc}
\hline $\begin{array}{l}\text { Binary } \\
\text { compound }\end{array}$ & $\begin{array}{l}\text { TO } \\
\text { phonon } \\
\left(\mathbf{c m}^{-1}\right)\end{array}$ & $\begin{array}{l}\text { LO } \\
\text { phonon } \\
\left(\mathbf{c m}^{-1}\right)\end{array}$ & $\begin{array}{l}\text { Atomic } \\
\text { weight of } \\
\text { group V }\end{array}$ \\
\hline InP [21] & 306.9 & 343.6 & 30.97 \\
InAs [20] & 217.3 & 238.8 & 74.92 \\
InSb [20] & 179.8 & 190.8 & 121.76 \\
\hline
\end{tabular}

Table 2. Phonon frequencies of the binary constituents, plus atomic weights of the corresponding group $\mathrm{V}$ atoms.

Given the samples were all nominally lattice-matched and assumed to be relaxed, the material stress was assumed to not contribute to the Raman spectra at the surface. Similarly, although the InAsSbP/InAs interface is thought to be type II [25], in our case the layers are sufficiently thick so that the substrate plays no part in the Raman spectroscopy. However, the peaks can become broadened due to the stresses induced from lattice mismatch. The optical penetration depth, $d_{o p t}=1 / 2 \alpha$, varies from $\approx 66 \mathrm{~nm}$ for InAs [26] to $\approx 85 \mathrm{~nm}$ for $\mathrm{InSb}_{0.32} \mathrm{P}_{0.68}$.

For a mixed alloy $\mathrm{AB}_{\mathrm{x}} \mathrm{C}_{1-\mathrm{x}}$, a simple criterion for predicting the mode behaviour has been proposed by I. F. Chang [27] in terms of the individual mass, denoted by $m$, and the reduced mass $\mu$. Such alloys show one-mode or partial two-mode behaviour if two conditions are satisfied: $m_{\mathrm{B}}>\mu_{\mathrm{AC}}$ and $m_{\mathrm{C}}>\mu_{\mathrm{AB}}$. Alloys show two-mode behaviour if $m_{\mathrm{B}}>\mu_{\mathrm{AC}}$ and $m_{\mathrm{C}}<\mu_{\mathrm{AB}}\left(m_{\mathrm{C}}<m_{\mathrm{B}}\right)$. According to this rule, InAsSb shows one-mode behaviour when the $\mathrm{Sb}$ mole fraction is smaller than 0.6 [13]. This concept can be expanded to quaternaries as well. Consequently, we would expect to see three Raman modes, from the InAs-, InSb- and InP-like binaries. Each of the corresponding binary compounds have the same group III element, and the Raman shift is roughly proportional to the inverse of the square root of the atomic mass of the group $\mathrm{V}$ element.

The samples grown in the immiscibility region, labelled C1900, C1898, $\mathrm{C} 1899$ and C1767, were clearly distinct from the other samples at low energies (fig. 2). They exhibit two principal peaks, labelled A and B, at approximately 138 and $145 \mathrm{~cm}^{-1}$, which are associated with disorder-activated longitudinal acoustic phonons (DALA), also seen in InAsSb ternary alloys [13], as well as a more prominent InSb-like LO peak. The InAs-like TO peak is forbidden in this geometry (since InAsSbP is a zinc blende structure), but is present in the spectra due to disorder. Several smaller peaks become apparent outside the immiscibility region. The peak at $115 \mathrm{~cm}^{-1}$ is thought to be from the $E_{1}$ mode of pure antimony. The $\mathrm{A}_{1 \mathrm{~g}}$ phonon mode of antimony occurs at $154 \mathrm{~cm}^{-1}$ [28], but is only noticeable in one sample as its intensity is too low compared to the DALA peaks. Two further peaks occur at 122 and $129 \mathrm{~cm}^{-1}$, of unknown origin, but are expected to be disorder related.

The InP-like LO peak becomes more noticeable with increasing phosphorus content, as expected, with an extra DAO peak inside the immiscibility region [29].

The spectra were deconvoluted into Lorentzian curves in order to better resolve peaks which were close to each other. As the forces between atoms depend on their neighbours, in a disordered alloy the phonon frequencies depend on the composition. 


\section{Raman scattering in $\operatorname{InAs}_{\mathrm{x}} \mathrm{Sb}_{\mathrm{y}} \mathbf{P}_{1-\mathrm{x}-\mathrm{y}}$ alloys grown by gas source MBE}

Figure 3 shows that both the InP-like TO and LO phonon peaks are observed throughout almost the entire compositional range and exhibited 0.182 and $0.256 \mathrm{~cm}^{-1}$ peak shifts per percent of phosphorus respectively.

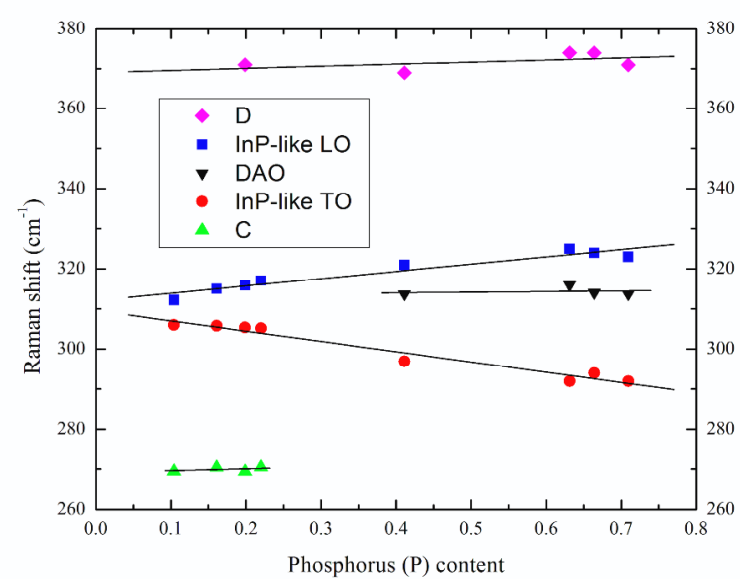

Figure 3. Raman peak shift with varying phosphorus concentration; the solid lines are linear fits.

Both InP-like LO and TO peak shifts change linearly with increasing phosphorus content, as given by equations (1) and (2) respectively.

$$
\begin{aligned}
& V_{I n P-L O}(x, y) \mathrm{cm}^{-1}=312+18(1-x-y) \\
& V_{I n P-T O}(x, y) \mathrm{cm}^{-1}=310-26(1-x-y)
\end{aligned}
$$

When the antimony and phosphorus mole fractions approach zero, the LO and TO modes converge to an isolated vibration mode, which is that of an isolated phosphorus atom in InAs, occurring at $310 \mathrm{~cm}^{-1}$ [29]. With increasing phosphorus content a further shoulder appears between the two peaks at $\approx 314 \mathrm{~cm}^{-1}$ and is associated with disorder activated optical (DAO) phonons [30]. The Raman signal from samples within the immiscibility region is much broader than those from samples outside the region. Peak D is very weak and is thought to be a second order effect associated with InSb-like 2LO phonons.

Peak C only appeared outside the of immiscibility region, with a very low intensity and was relatively insensitive to composition. As it only appears when the arsenic concentration is $>0.6$ it is thought to be associated with InAs. A phonon peak at $270 \mathrm{~cm}^{-1}$ was assigned to additive combination
TO+TA $(\Delta \rightarrow \mathrm{K})$ in InAs with a nearby 2LA peak by R. Carles [31].

(a)

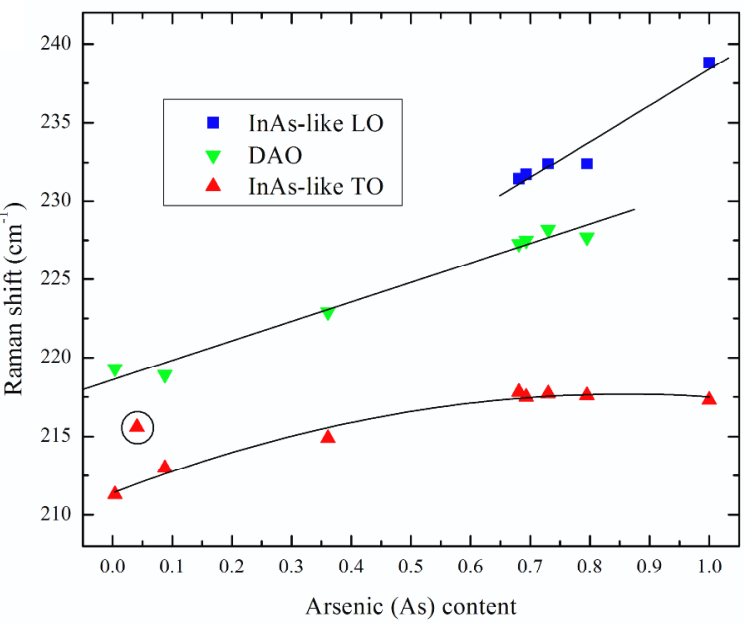

(b)

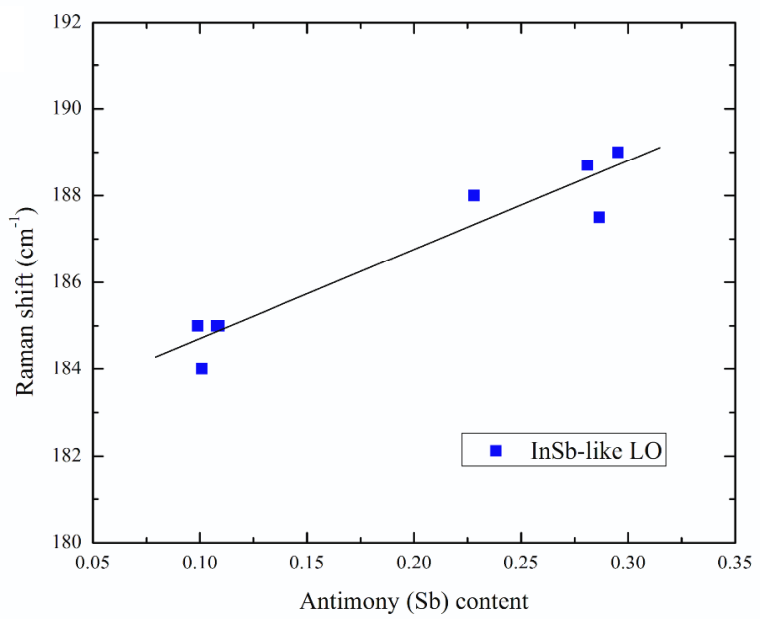

Figure 4. Raman peak shift with varying concentrations of (a) arsenic and (b) antimony in the alloy. The solid lines are linear and quadratic fits. The circled point is a combination of two indistinguishable peaks.

Figure 4(a) shows the dependence of the InAs-like phonon peaks on the arsenic content in the alloy. (The values for pure InAs from table 2 were also included.) The InAslike LO peak was only observed at high arsenic concentrations, with a linear shift of $0.229 \mathrm{~cm}^{-1}$ per percent of arsenic. But, the TO peak was found to more closely fit the parabolic dependence described by equation (4). (We were unable to distinguish the TO peak for the second sample from the nearby peak.) Another DAO peak appears as a shoulder between the InAs-like TO and LO peaks. Such a DAO peak 


\section{Raman scattering in $\operatorname{InAs}_{\mathrm{x}} \mathrm{Sb}_{\mathrm{y}} \mathbf{P}_{1-\mathrm{x}-\mathrm{y}}$ alloys grown by gas source MBE}

has been previously reported in similar materials [32], and was observed here with a greater intensity than even the InAs-like TO for samples C1900 and C1767. There was no peak observed for C1898 $\left(\operatorname{InAs}_{0.0408} \mathrm{Sb}_{0.2952} \mathrm{P}_{0.664}\right)$, we suppose that this is because it becomes indistinguishable from the DAO peak.

$$
\begin{gathered}
v_{\text {InAs-LO}}(x) \mathrm{cm}^{-1}=215.5+23 x \\
(0.65 \leq x \leq 1.0) \\
v_{\text {InAs-TO }}(x) \mathrm{cm}^{-1}=211.4+14.6 x-8.5 x^{2}
\end{gathered}
$$

The full width at half-maximum (FWHM) of the InAs-like TO peak varied from about $9 \mathrm{~cm}^{-1}$ at very low arsenic concentration to $\sim 20 \mathrm{~cm}^{-1}$ for the arsenic-rich samples. The FWHM for the InAs-like LO peak remained constant at $\sim 4 \mathrm{~cm}^{-1}$, while the nearby DAO stayed constant at $\sim 6 \mathrm{~cm}^{-1}$. The FWHM of the InP-like LO peak was found to be approximately constant at $\sim 9 \mathrm{~cm}^{-1}$, which indicates good crystalline quality, while the nearby DAO was slightly wider at $\sim 15 \mathrm{~cm}^{-1}$. However, the FWHM of the InP-like TO peak increased to $\sim 20 \mathrm{~cm}^{-1}$ with increasing phosphorus concentration, suggesting increased alloy disorder.

Investigating the antimony component, as shown in figure 4(b), revealed that the Raman shift of the InSb-like LO peak had similar linear dependence on composition as the InP-like peaks.

$V_{I n S b-L O}(y) \mathrm{cm}^{-1}=183+20 y$

$$
(0.05 \leq y \leq 0.30)
$$

The InAs-like LO peak is more easily observed than the InSb-like LO peak for similar alloy compositions of arsenic and antimony due to the polarization field being larger for higher energy modes, and hence the electron-phonon interaction is enhanced [33]. The second-order 2LO peak from InAs at $\sim 478 \mathrm{~cm}^{-1}$ was not easily observed and was thought to be too weak to distinguish from the background noise.

\section{Conclusion}

In summary, quaternary $\operatorname{InAs}_{\mathrm{x}} \mathrm{Sb}_{\mathrm{y}} \mathrm{P}_{1-\mathrm{x}-\mathrm{y}}$ alloys (covering a wide compositional range of $0.040 \leq \mathrm{x} \leq 0.795, \quad 0.099 \leq \mathrm{y} \leq 0.285) \quad$ which were grown by MBE nominally lattice matched to InAs were investigated using room temperature Raman spectroscopy. The alloy was confirmed to exhibit three-mode behaviour across part of the composition range. InP-like LO and TO phonons were observed over the entire compositional range, InAs-like LO phonons were only observed at high arsenic concentrations and no InSb-like TO phonons were observed at all. Increased DALA phonon signals were observed for alloy compositions within the miscibility gap. It is evident that Raman spectroscopy can provide detailed and rapid diagnostic information about structural disorder and the onset of phase separation in this technologically important alloy system.

\section{Acknowledgements}

The authors are grateful to the Engineering and Physical Sciences Research Council (EPSRC) for providing a studentship for K. J. Cheetham and to Dr. Frank Martin at the Lancaster University Centre for Biophotonics for providing access to the Raman facilities.

\section{References}

${ }^{1}$ Krier A, Yin M, Smirnov V, Batty P, Carrington P J, Solovev V and Sherstnev V, 2008 Phys. stat. sol. (a) 205, 1, 129-43

${ }^{2}$ Krier A and Suleiman W, 2006 Applied Physics Letters 89, 083512, (2006)

${ }^{3}$ Zotova N V, Kizhaev S S, Molchanov S S, Voronina T I, Lagunova T S, Pushnyi B V and Yakovlev Y P, 2003 Semiconductors 37, 8

${ }^{4}$ Gao H H, Krier A, Sherstnev V and Yakolev Y, 1999 Journal of Physics D: Applied Physics 32, 1768-72

${ }^{5}$ Krier A, Gao H, Sherstnev V, Yakovlev Y, 1999 Electronics Letters (USA) 35, 1665-7

${ }^{6} \mathrm{~N}$ Kobayashi and Horikoshi Y, 1980 Japanese Journal of Applied Physics 19, L 641

${ }^{7}$ Imenkov A N, Kolchanova N M, Yakovlev Y P, Kubát P, and Civiš S, 2001 Review of Scientific Instruments 72, 1988

${ }^{8}$ Krier A, Mao Y, 1997 Infrared Physics \& Technology 38, 7, 397-403

${ }^{9}$ Chakrabarti P, Krier, A and Morgan A F, 2003 IEEE Transactions on Electron Devices 50, 10, 2049-58

${ }^{10}$ Krier A and Mao Y, 1997 IEE Proceedings Optoelectronics 144, 355

${ }^{11}$ Cheetham K J, Carrington P J, Cook N and Krier A, 2010 Solar Energy Materials and Solar Cells, doi:10.1016/j.solmat.2010.08.036, in-press

${ }^{12}$ Wilson M R, Krier A, Mao Y, 1996 Journal of Electronic Materials 25, 9, 1439-45

${ }^{13}$ Cherng Y T, Ma K Y and Stringfellow G B, 1988 Applied Physics Letters 53 (10), 886-7 
${ }^{14}$ Drews D, Schneider A, Werninghaus T, Behres A, M. Heuken, K. Heime and D. R. T. Zahn, 1998 Applied Surface Science 123-124, 746-50

${ }^{15}$ Carles R, Saint-Cricq N, Renucci J B, and Nicholas R J, 1980 Journal of Physics C: Solid St. Phys. 13, 899-910

${ }^{16}$ Olvera-Hernández J, Olvera-Cervantes J, RojasLópez M, Navarro-Contreras H, Vidal M A, and de Anda F, 2006 Journal of Physics: Conference Series 28, 147-50

${ }^{17}$ V. Vorlícek, K. D. Mosieev, M. P. Mikhailova, Yu. P. Yakovlev, E. Hulicius, and T. Šimecek, 2002 Crystal Research and Technology 37 (2-3), 259-67

${ }^{18}$ Tsai G, Wang D and Lin H, 2008 Journal of Applied Physics 104, 023535

${ }^{19}$ Tsai G, Wang, Wu C, Wu C, Lin Y and Lin H, 2007 Journal of Crystal Growth 301-302, 134-8

${ }^{20}$ Chen J, Tyan S and Wu M, 1998 Japanese Journal of Applied Physics 37, L1365-L1366

${ }^{21}$ Lin H and Lee M, 1996 Chinese Journal of Physics 34, 3-I, 804

${ }^{22}$ Stringfellow G B, 1974 Journal of Crystal Growth 27, 21

${ }^{23}$ Frost F, Lippold G, Schindler A and Bigl F, 1999 Journal of Applied Physics 85, 8378

${ }^{24}$ Irmer G, 1990 EMIS Datareview Series 6, 207-11

${ }^{25}$ Krier A, 2001 Phil. Trans. of The Royal Society A. 359, 599-619

${ }^{26}$ Aspnes D E and Studna A A, 1983 Physical Review B 27, 2, 985-1009

${ }^{27}$ Chang I F and Mitra S S, 1968 Physical Review 172 (3), 924-33

${ }^{28}$ Rettweiler U, Richter W, Resch U, Geurts H, Sporken R, Xhonneux P and Caudano R, 1989 Journal of Physics: Condensed Matter 1, SB93SB97

${ }^{29}$ Carles R, Saint-Cricq N, Renucci J B, and Nicolas R J, 1980 Journal of Physics C: Solid State Physics 13, 899-910

${ }^{30}$ Lung-Chien Chen, Shing-Long Tyan, and MengChyi Wu, 1998 Japanese Journal of Applied Physics 37, 1365-6

${ }^{31}$ Carles R, Saint-Cricq N, Renucci J B, Renucci M A and Zwick A, 1980 Physical Review B 22 (10), 4804-15

${ }^{32}$ Li Y B, Dosanjh S S, Ferguson I T, Norman A G, de Oliveira A G, Stradling R A and Zallen R, 1992 Semiconductor Science and Technology 7 (4), 56770

${ }^{33}$ Nash K J, Skolnick M S and Bass S J, 1987 Semiconductor Science and Technology 2 (6), 329 


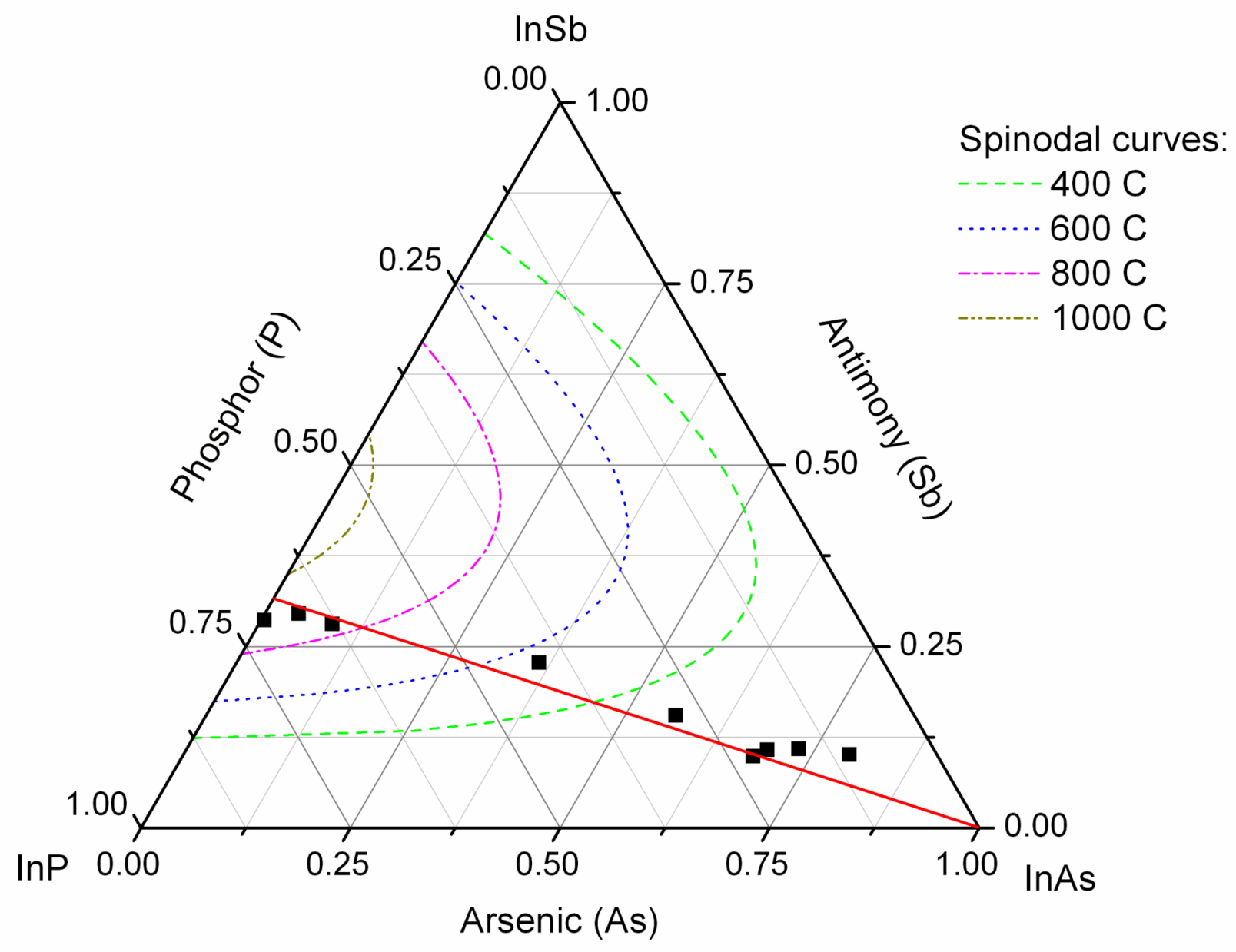

Figure 1 (Figure1.tif) 


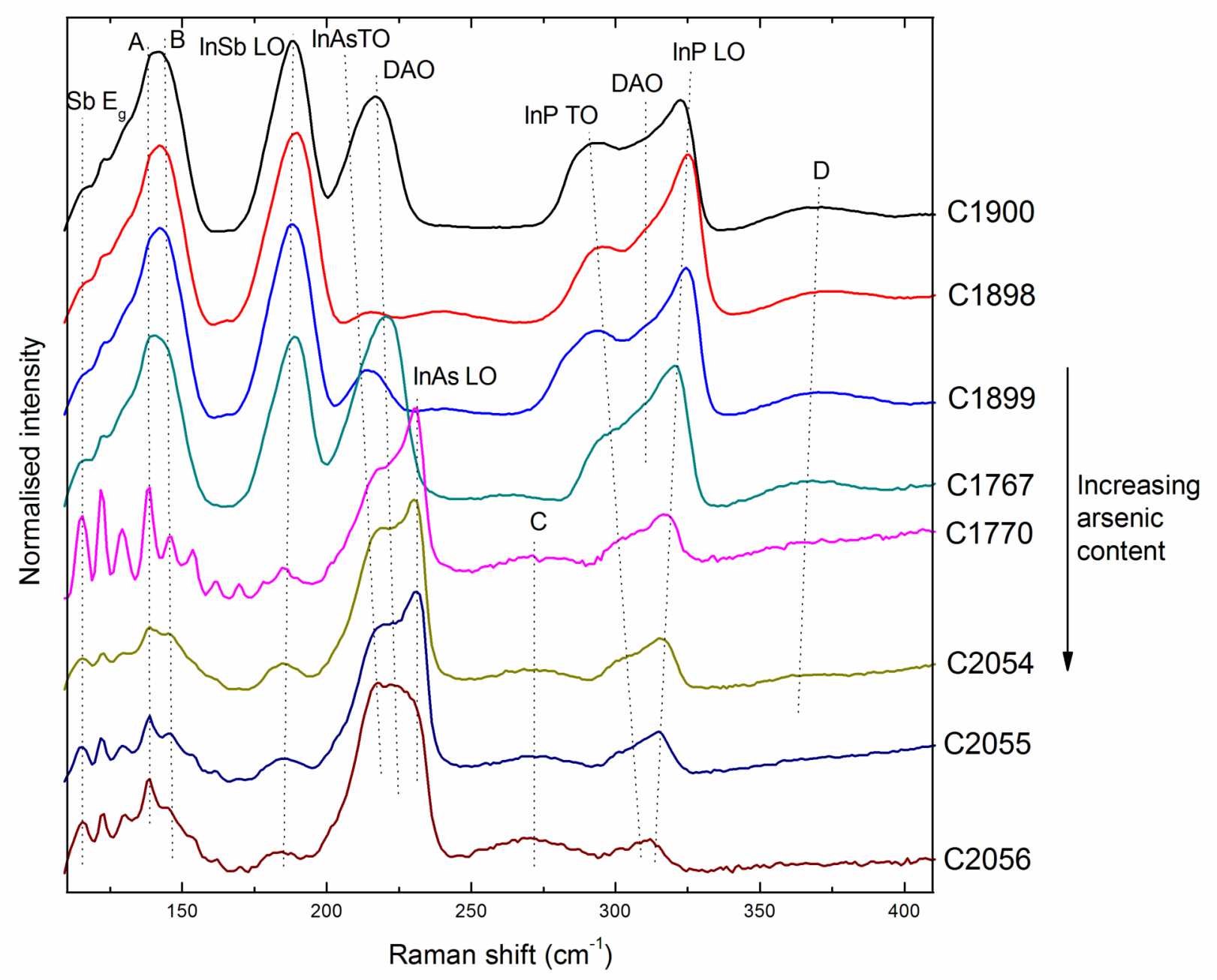

Figure 2 (Figure2.tif) 


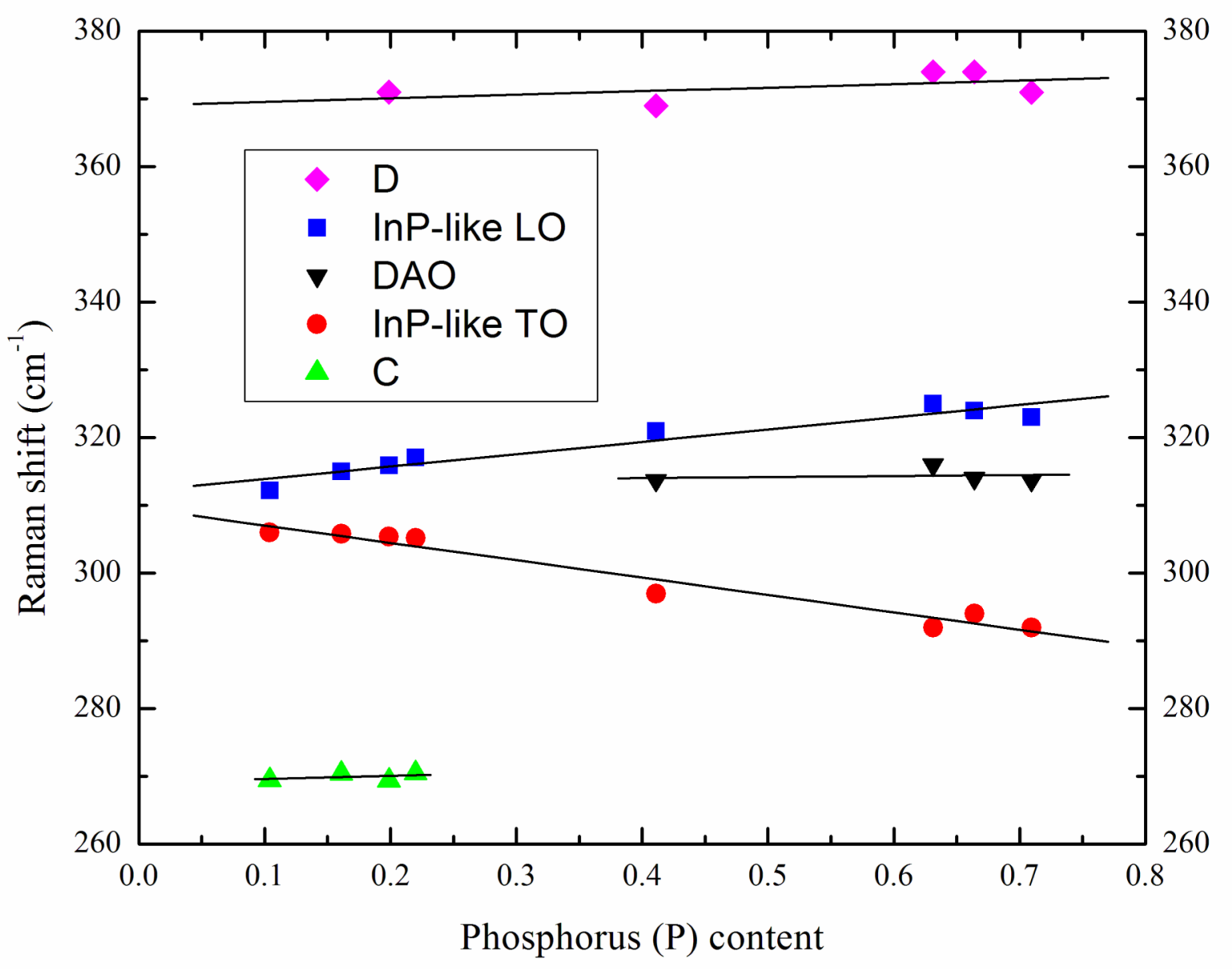

Figure 3 (Figure3.tif) 


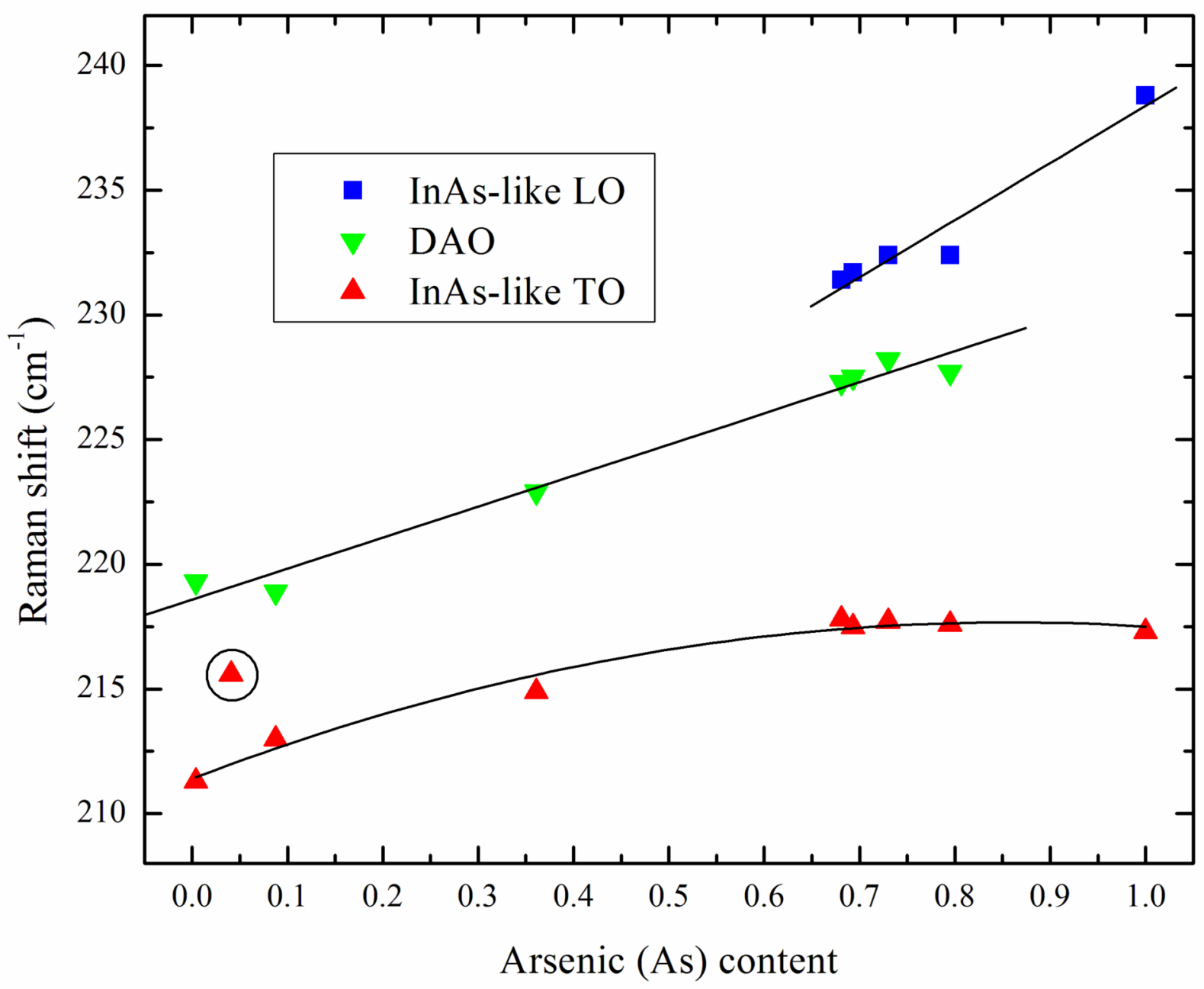

Figure 4a (Figure4a.tif) 


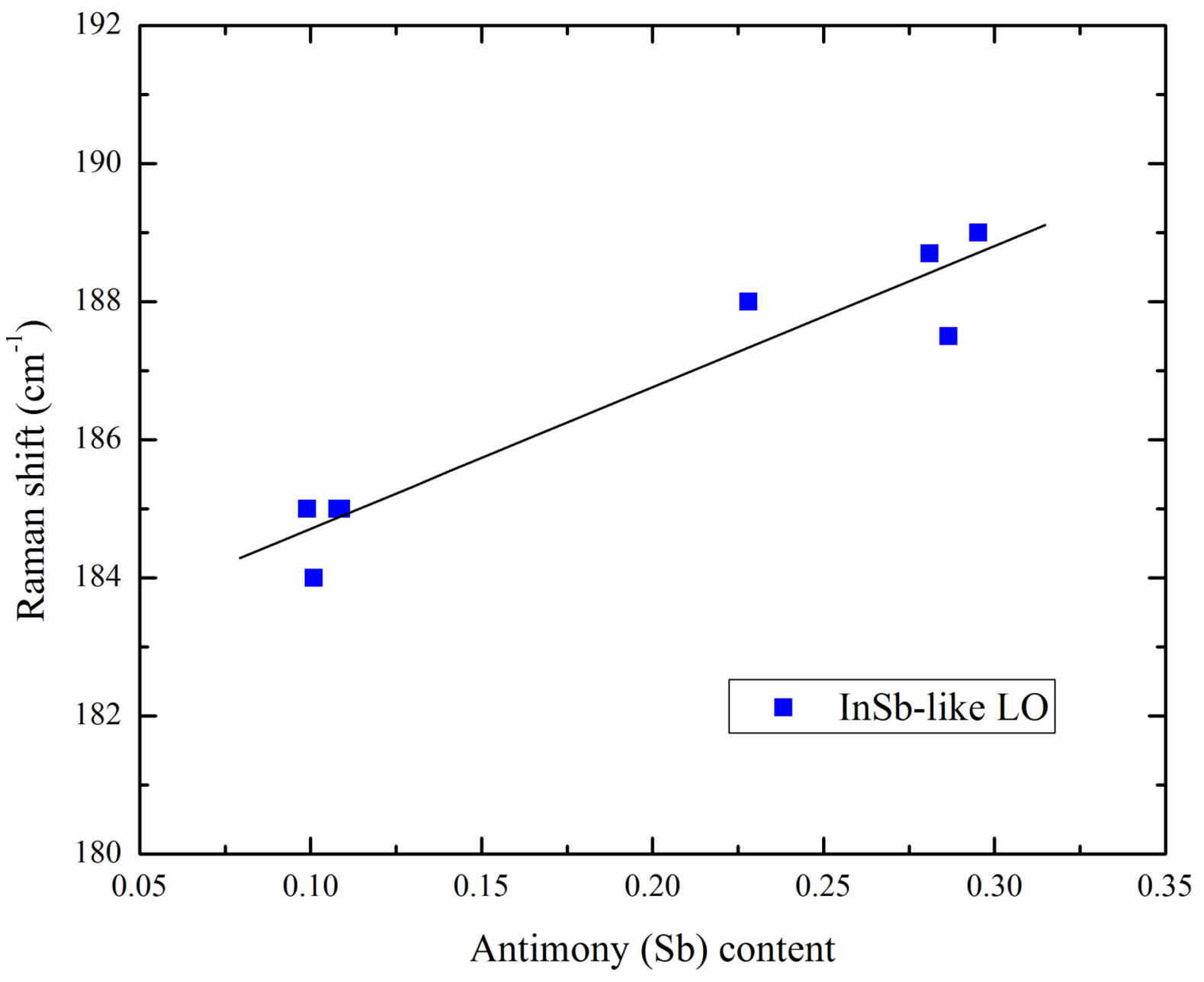

Figure 4b (Figure4b.tif) 